\title{
DESAIN DAN PEMBUATAN PAKAIAN KERJA KULIT
}

\author{
TH. Widiarti ${ }^{1)}$
}

\section{INTISARI}

Pembuatan pakaian kerja dari kulit bertujuan untuk menambah keanekaragaman garmen kulit, mencari suatu cara yang praktis dan mudah untuk membuat garmen kulit. Disamping itu juga untuk mendapatkan model yang cocok untuk pakaian kerja berat.

Telah dibuat delapan rancangan pakaian kerja berat dari kulit, kemudian diadakan pemilihan rancangan yang paling disukai oleh sepuluh orang panelis. Berdasarkan hasil pemilihan rancangan, kemudian dibuat pakaian kerja dari kulit dalam bentuk prototip Proses pembuataninya meliputi pembuatan pola dasar dengan sistem ukuran standar, pemotongan bahan, preparasi dan penjahitan. Hasil yang dicapai adalah tiga potong pakaian kerja berat dari kulit dengan ukuran 48 (M), sedangkan model yang disukai adalah Gambar 1., Gambar 2. dan Gambar 3., sesuai dengan rancangan yang terpilih. Prototip yang dibuat dinilai oleh sepuluh orang panelis dengan hasil : pakaian kerja gambar rancangan dua dan tiga dinilai baik, sedangkan nomor satu cukup baik. Hasil penilaian menunjukkan Gambar 1. cukup baik, karena mutu bahan dasar yang dipilih bermutu cukup. Sedangkan pakaian kerja Gambar 2. dan Gambar 3., hasilnya baik karena mutu bahan dasarnya baik. Dengan terpenuhinya persyaratan teknis, maka hasil produksi yang bermutu baik akan tercapai.

The preparation of leather custom for hard workers was aimed to increase the diversification of leather good products garment, to obtain a practical and simple method of leather garment preparation, as well as to seek suitable fashion of hard workers wear.

Eight designs prepared, of leather costum for hard workers followed by selection of the most favourite designs by ten panelists. Based on the selected designs, the leather costum were then prepared. The manufacturing of the leather garment was carried - out in sequence of the following works, basic pattern preparation performed in mass production system, in standard size, material cutting, preparation for assembling and stitching. Three pieces of leather garment for hard workers were produced in size $48(\mathrm{M})$ for this purpose, where as the most favourite designs were 1,2 and 3. Leather garment for hard workers of designs one, two and three met good marks, while design 1 was fair. Technology of manufacturing obviously affected the quality of leather garment for hard workers, as well as the selection of the raw materials quality. The result of study could be presented as the following design one for quality of material was fair. Design two and three met good mark for the higher quality of raw material was utilised to manufacture high quality leather garment for hard workers some considerations should be taken, they are : economical use of raw material; practice simple styles; and proporsional lines and sizes. The conformity of the technical requirements will produce sound quality products.

1) Balai Besar Penelitian dan Pengembangan Industri Barang Kulit, Karet dan Plastik Yogyakarta 


\section{PENDAHULUAN}

Pakaian kerja dari kulit ini dipakai oleh mereka yang bekerja misalnya di Pertamina, pengeboran minyak lepas pantai dan pekerjaan sejenis. Dalam melaksanakan pekerjaan tersebut sangat diperlukan pakain kerja yang dapat melindungi dari pengaruh udara panas atau angin, namun masih tetap memberi kenyamanan pakai, jenis pakaian yang memenuhi persyaratan tersebut, dibuat dari kulit tersamak yang mempunyai sifat demikian. Pakaian kerja dari kulit ini dibuat karena adanya permintaan dan sejalan dengan kegiatan yang tercantum dalam GBHN yaitu meningkatkan sumber daya manusia oleh karena itu diperlukan adanya penguasaan teknik yang memadai oleh personil yang bergerak dalam bidang pembuatan garmen kulit.

Menurut Carlo Pallizzoto (1989), pembuatan celana panjang pria berdasarkan tinggi badan pria dengan tinggi rata - rata $168 \mathrm{~cm}$, dan pembagian modulus tinggi badan sebesar 7,5 bagian, sehingga tiap modulus tinggi mempunyai ukuran $168: 7,5=22,4 \mathrm{~cm}$.

Pembagian modulus tinggi badan ini digunakan untuk pembuatan pola dengan ukuran Standar 48 (M) yaitu :
$1 / 2$ lingkar pinggang :
$48 \mathrm{~cm}$
$1 / 2$ lingkar pinggul : $50 \mathrm{~cm}$

Berdasarkan ukuran tersebut dapat dibuat pakaian kerja berat dari kulit dengan mengkombinasikan tentang pembuatan pola dasar jaket "Unisex " dan pembuatan celana panjang pria.

Porrie Muliawan (1982) menyebutkan bahwa celana pada umumnya terdiri atas empat bagian yaitu 2 helai bagian muka dan bagaian belakang. Jadi bagian sisi dan tengah muka belakang ada kampuh.

Jenis ukuran untuk membuat celana panjang dan cara mengukurnya juga sama, hanya ada kelainan dalam ukuran panjang celana.

Menurut Sotja Prajati (1991). Cara dan teknik pembuatan Garmen meliputi, pemotongan bahan, cara pemberian lapis antara, perakitan, tahapan penjahitan. pemasangan kain lapis, perlakuan akhir ( Balai Besar Penelitian dan Pengembangan Industri Barang Kulit, Karet dan Plastik )

Sedangkan menurut SNI .06-0250-1989 Mutu dan cara uji Kulit Sarung Tangan dan Jaket Domba / Kambing ditentukan :

Organoleptis, dengan penglihatan mata dan dengan cara dipegang.

Kulit tidak gembos Nerf dikatakan gembos atau lepas bila kerutan-kerutan yang terbentuk itu besar runcing jumlah kerutan-kerutan tiap $1 \mathrm{~cm}$ adalah sedikit, kulit dikatakan liat bila kerutan yang terbentuk itu halus, kecil-kecil dan berjumlah banyak dalam tiap-tiap $\mathrm{Cm} 2$ nya, nerf harus liat pada bagian kroupon, leher dan perut.

\section{Ketahanan Gosok Cat.}

Diambil contoh sebanyak 2 potong dengan ukuran panjang $12,5 \mathrm{~cm}$, lebar $5 \mathrm{~cm}$ Sepotong untuk pengujian dengan kain putih kering, Sepotong lagi untuk pengujian dengan kain putih basah. Kulit dipasang pada pesawat crookmeter. Pemutaran dimulai hingga, kulit tergosok dengan kain putih kering sebanyak $10 \mathrm{x}$ selama 10 detik. Kemudian kain diangkat dan diperiksa warnanya. 
Dengan kain yang baru, yang sudah dibasahkan hingga berisi 75 sampai $100 \%$ air pekerjaan diteruskan dengan menggunakan kulit yang sepotong lagi.

Hasil pengujian dinyatakan sebagai berikut :

Baik : Jika tidak/sedikit sekali luntur dengan kain basah

Sedang : Jika luntur dengan kain basah, tetapi tidak atau sedikit sekali luntur dengan kain kering

Jelek : Jika luntur dengan kain kering

\section{Tujuan}

- Menambah keanekaragaman garmen kulit

- Mencari teknik pengerjaan yang praktis dan mudah dikerjakan

- Mencari model yang tepat untuk pakaian kerja berat

\section{BAHAN DAN METODA PENELITIAN}

\section{Bahan Penelitian}

\section{Bahan Baku}

Bahan baku penelitian ialah kulit Domba dan atau Kambing sebanyak 210 kaki persegi terdiri atas tiga jenis warna yaitu abu-abu, coklat dan hitam.

Kain Blaco, untuk pembuatan pra prototip, dari bahan katun.

\section{Bahan Pembantu}

Kain lapis dengan warna yang sesuai dengan warna kulit., kain ero putih untuk pelapis antara; Benang poliester ( astra no. 24 ); katup Sleret; kancing.

\section{Peralatan}

Mesin jahit pfaff 34 Lockstich Flatbed sewing machine dan Singer model 491 D. 300 CA dengan dynamo dan Seterika ( Toyomi, 220 Volt, 450 watt ).

\section{Metoda}

Pembuatan rancangan desain dan pemilihan desain.

Desain yang sudah dibuat sebanyak delapan buah, Kemudian diadakan pemilihan untuk desain yang paling disukai sebanyak tiga buah, sebagai sampel, dengan mencantumkan nomor desainnya.

Pemilihan ini dilakukan oleh 10 orang panelis.

Adapun desain yang disukai adalah : Desain Pakaian Kerja Gambar Satu, Gambar dua dan Gambar tiga.

Desain yang terpilih inilah yang akan dibuat prototipnya. 


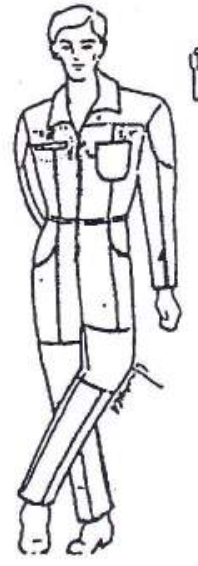

Gambar 1

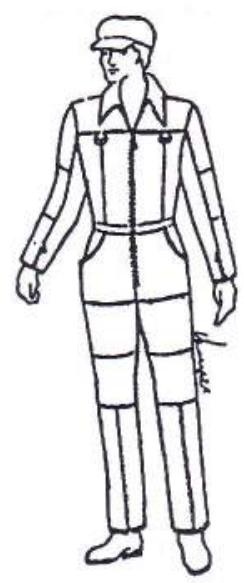

Gambar 2
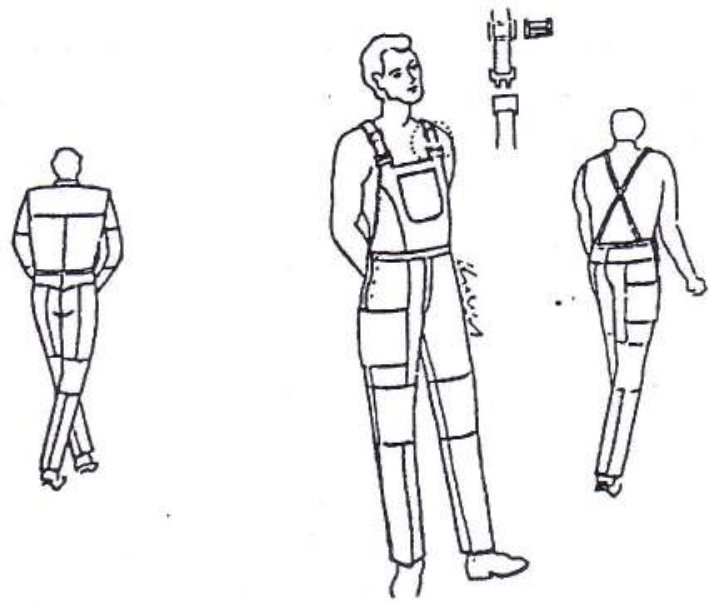

Gambar 3

- Pembuatan Pola

Pola pakaian kerja dibuat dengan pola dasar celana panjang pria dan Jaket " Unisex “. Pecah pola, pola lengkap, dibuat sesuai desain terpilih, dengan ukuran tinggi badan 170 $\mathrm{cm}$, ukuran badan $48(\mathrm{M})$.

- Pembuatan pra prototip

Pembuatan pra prototip pakaian kerja berat ini dibuat dari bahan kain belaco, model sesuai dengan desain terpilih yaitu

Satu potong pakaian kerja berat ukuran 48 seperti gambar satu.

Satu potong pakaian kerja berat ukuran 48 seperti gambar dua.

Satu potong pakaian kerja berat ukuran 48 seperti gambar tiga

Seluruhnya berjumlah tiga potong pakaian kerja dari kain; yang dibuat oleh satu orang, adanya kekurangan yang dijumpai pada saat menjahit potongan-potongan untuk pra prototipe, dipakai sebagai dasar perbaikan untuk pembuatan prototipe dari kulit.

Pembuatan Prototip

Prototip pakaian kerja berat ini dibuat dari kulit Jaket (domba) Samak khrom, sebanyak tiga potong.

Tahapan yang perlu diikuti dalam pembuatan prototipe adalah sebagai berikut.

\section{Urutan Proses Pembuatan :}

1. Proses persiapan rancangan desain

Rancangan desain, dipersiapkan oleh seorang desainer, kemudian dipilih desain terbaik untuk dibuat prototip pakaian kerja kulit, disajikan pada gambar satu, dua dan tiga.

2. Proses Pemotongan pola dan bahan

Dibuat pola dengan menggunakan kertas malaga, sesuai dengan rancangan desain satu, dua dan tiga, dicek jumlah potongannya, serta tanda-tanda penjahitan.

Selanjutnya dipilih lembaran kulit yang tidak cacat, pola diletakkan diatas lembaran kulit yang berada pada permukaan meja datar, lembaran kulit dipotong sesuai pola yang diinginkan, dengan menggunakan pisau (cutter), kain lapis dipotong dengan gunting, sesuai pola untuk 
kain, kain pelapis antara dari kain ero, dipotong sesuai dengan bentuk-bentuk pola dari bagian-bagian yang akan diberi pelapis, agar memberi kesan tegak dan rata.

3. Preparasi

Preparasi adalah segala perlakuan pra penjahitan, yaitu berupa perakitan pelapis antara dan kulit, pelipatan kulit pada bagian bagian yang diinginkan, merakit bagian yang akan dijahit untuk digabungkan.

4. Penjahitan

Penggabungan kulit dan kain lapis serta penyelesaian akhir sebagai berikut.

- Potongan bagian lengan, krah, badan atas depan dan belakang serta ban pinggang, dijahit menjadi satu bagian utuh.

- Bagian depan atas dan belakang atas, dijahit pada bagian pundak, jahit bagian lengan pada kerungnya, krah dipasang pada kerung leher yang terdapat pada badan atas depan dan belakang dengan jahit setik balik.

- Kain lapis bagian atas dijahit dengan urutan seperti penjahitan kulit, pada kain lapis ini bagian pinggang dipasang ban kulit.

- Bagian celana depan dan belakang beserta saku dan tempat alat dirakit dengan menggunakan lem kuat, dilanjutkan dengan jahit setik balik dan tindas, dimulai dari sisi dalam dan luar, diteruskan dengan menjahit bagian mestak, sehingga menjadi satu bagian yang utuh.

- Potongan kain lapis, untuk celana dengan panjang sampai batas lutut di jahit setik

- Bagian atas dan bagian bawah (celana), masing-masing baik yang dibuat dari kulit
maupun dari kain lapis digabungkan melalui ban pinggang dengan jahit tindas. Bagian

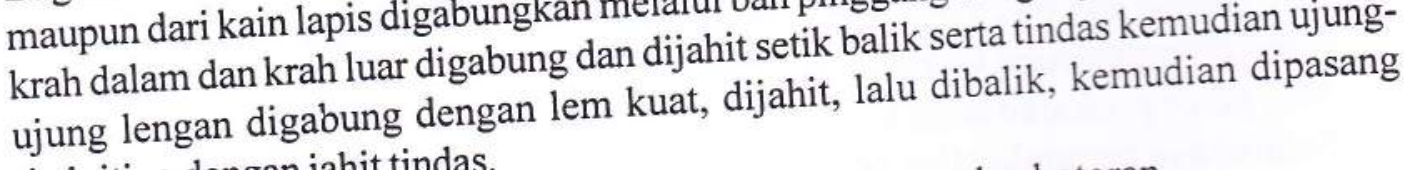
ritsluiting dengan jahit tindas.

- Terakhir pakaian kerja kulit, dibersihkan dari sisa benang dan kotoran.

5. Prototip dievaluasi oleh 10 orang panelis yang mengerti tentang garmen kulit, penilaiannya meliputi.

Kerapian jahitan dilakukan dengan sempurna, tidak terjadi kesalahan yang mempengaruhi hasil akhir prototip.

Pemasangan kain lapis, tepat dan rapi, tidak bergelombang.

Pemasangan katup sleret dan kancing, dipasang dengan tapat, dapat dibuka dan ditutup dengan mudah, dan berfungsi dengan baik.

Model, tidak terlalu rumit, symetri, proporsional, serta mempunyai susunan letak potonganpotongan yang menarik dengan ukuran-ukuran yang tepat, sehingga dapat menarik perhatian.

Kriteria Penialaian Kerapian Penjahitan

Nilai 1 : banyak kesalahan pada penjahitan, jahitan kendor tidak kuat meloncat atau menumpuk, jarak jahitan dari tepi kulit tidak sama, jarak jahitan tidak teratur per 1 cmnya, tidak rapi dan sambungan tidak tepat.

Nilai 2 : beberapa kesalahan pada hasil penjahitan, seperti tersebut diatas tetapi jumlah kesalahannya lebih sedikit.

Nilai 3 : kesalahan yang jumlahnya makin sedikit, misalnya hanya tidak rapi dan kurang kuat saja.

Nilai 4 : hanya terdapat satu kesalahan misalnya sambungan tidak tepat atau kesalahan 
lain, yang hanya satu kesalahan saja.

Nilai 5 : penjahitan dilakukan dengan sempurna.

Pemasangan Kain Lapis

Nilai 1 : banyak kesalahan pemasangan lapis, kendor, tidak rata, tidak tepat dan bergelombang jahitan ada yang melomcat.

Nilai 2 : beberapa kesalahan pemasangan lapis, tidak tepat dan bergelombang tidak rata.

Nilai 3 : kesalahan pemasangan lapis, tidak tepat, tidak rata.

Nilai 4 : ada satu kesalahan, misalnya : pemasangan kain lapis

Nilai 5 : tidak ada kesalahan pemasangan kain lapis.

Pemasangan Katup Sleret / Kancing

Nilai 1 : banyak kesalahan, pemasangan, warna, ukuran, bentuk jarak dan tempat kedudukan tidak tepat.

Nilai 2 : beberapa kesalahan ukuran dan jarak kancing kurang tepat, atau pemasangan kancing kurang tepat.

Nilai 3 : kesalahan pemasangan kancing atau ritsluiting misalnya kedudukan tidak tepat, jahitanya tidak rata.

Nilai 4 : ada satu kesalahan, misalnya : pada pemasangan kancing atau ada jahitan yang meloncat dan kemudian dijahit ulang, ataupun kesalahan lain tetapi tidak lebih dari satu kesalahan.

Nilai 5 : pemasangan kancing dan ritsluiting sempurna.

Model

Nilai 1 : Model tidak proporsional perbandingan tiap bagiannya terlalu rumit, karena banyak terdapat sambungan yang asymestris dan banyak variasi.

Nilai 2 : Model kurang proporsional, perbandingan tiap bagiannya, tetapi terdapat sambungan yang asymetris atau banyak variasi.

Nilai 3 : Model cukup proporsional perbandingan tiap bagiannya, tetapi terdapat banyak sambungan yang asymetris atau banyak variasi.

Nilai 4 : Model proporsional perbandingan tiap bagiannya, tetapi masih ada satu kekurangan misalnya sambungan asymetria ataupun terlalu banyak variasi.

Nilai 5 : Model dibuat sederhana tetapi menarik karena tidak banyak terdapat variasi yang tidak perlu, sambungan asymetris dihindari

Kriteria penilaian tersebut digunakan sebagai acuan untuk menilai, kerapian jahitan, kerapihan pemasangan kain lapis, pemasangan katup steret atau kancing serta model.

\section{HASIL DAN PEMBAHASAN}

Hasil yang dicapai berupa tiga buah prototip pakaian kerja berat dari kulit seperti pada Gambar satu, dua dan tiga, masing-masing jenis pakaian dibuat dalam warna abu-abu, coklat dan hitam.

Hasil penilaian terhadap ketiga model tersebut sebagai berikut :

Model satu merupakan pakaian kerja Kulit yang dibuat dari potongan-potongan kulit, 
pada setiap bagiannya dibuat proporsional dan symetris sesuai dengan pola, sambungan pada bagian lengan dibuat dengan bentuk melengkung dan dimaksudkan sebagai variasi, sambungan-sambungan jahitan disesuaikan dengan keluasan kulit. Model ini dilengkapi dua saku yang terletak pada bagian dada, dipergunakan untuk menyimpan peralatan kecil yang dibutuhkan pada waktu bekerja.

Model dua, merupakan pakaian kerja kulit, juga dibuat dari potongan-potongan kulit, setiap bagiannya dibuat secara proporsional, dan symetris sesuai dengan pola, akan tetapi sambungan pada lengan berbentuk lurus, dan ini tidak mengurangi penampilan yang menarik pada pakaian kerja kulit yang dilengkapi variasi pada bagian depan dengan $\mathrm{D}$ ring yang disamping mempermanis penampilan, juga berfungsi untuk mengaitkan, misal kunci laci almari, walaupun lebih sederhana, tanpa adanya variasi saku pada bagian dada, pakaian kerja kulit ini lebih menampilkan kesan enak dipandang.

Model tiga, merupakan pakaian kerja kulit, yang dibuat dari potongan-potongan, setiap bagiannya dibuat proporsional, model ini tanpa lengan, pemakaiannya dapat dipadukan dengan pakaian dalam dari bahan tekstil misalnya kaos berlengan panjang, dan dimaksudkan agar di dapat keaneka ragam pakaian kerja kulit; menurut perhitungan tekno ekonominya lebih murah dan model ini masih menampilkan variasi saku yang ada pada bagian dada serta pada bagian paha. Tali bahu, dihiasi dengan gesper, yang berfungsi sebagai pengikat tali bahu, dapat disetel sesuai dengan ukuran pemakainya, disamping juga dapat berfungsi sebagai aksesori.

Model desain pakaian kerja pada gambar dua dan tiga dinilai baik, Sedangkan untuk gambar satu dinilai cukup baik. Pakaian kerja dua dan tiga desainnya dinilai baik, karena gambar satu dinilai cukup baik. Pakaian kerja dua diap bagiannya lebih proporsional, tidak
model dibuat lebih sederhana perbandingan pada tiak sesoris yang tidak perlu.
banyak didapat sambungan asymetris, tidak banyak digunakan akser

Sedangkan model satu nilainya cukup baik karena model dibuat agak rumit, banyak sambungan asymetris, dan melengkung atau membentuk sudut lancip, seperti bagian punggung dan pinggang ( bagian belakang bawah ). Disamping itu adanya variasi pada bagian depan, yang dibuat agak berlebihan sehingga berpengaruh pada hasil kerapihan penjahitan, dimana diperlukan tingkat ketrampilan menjahit yang memadai, supaya hasil jahitannya bermutu baik.

Dalam membuat pakaian kerja berat dari kulit, pada pembuatannya tidak diperlukan permainan kombinasi warna, hal ini dilakukan untuk menghindari kesan fashionable, penekanannya ada pada keseimbangan setiap bagiannya yang dibuat menarik, tepat dan sesuai ukurannya.

Sederhana, tetapi menarik dengan warna yang bernuansa cenderung gelap dan tidak menyolok, supaya memberi kesan jantan dan gagah, disamping itu juga enak dipandang.

Pertimbangan lain yang tidak kalah penting adalah fungsi dari pakaian kerja lebih ditekankan pada keenakan pakai, agar tidak menghambat didalam melaksanakan pekerjaan. Faktor-faktor lain yang berpengaruh terhadap pakaian kerja berat dari kulit agar dapat dikategorikan baik adalah :

- Pemilihan bahan dasar

Bahan dasar dipilih dari kulit jaket domba kambing samak khrom, dengan ketebalan cukup $(0,8-1,0) \mathrm{mm}$. dan rata kelemasan cukup, ketahanan gosok catnya tidak luntur. Pada pakaian kerja berat model dua dan tiga, kulit yang dipilih sudah memenuhi syarat, sedangkan pada model satu, kulit tebalnya tidak rata, sehingga terjadi penebalan yang 
berlebihan pada sambungan, akibatnya hasil penjahitan menjadi kurang rapi.

- Bahan pembantu

- Kain lapis dari bahan saten dengan mutu yang baik warna dipilih sesuai dengan warna bahan dasarnya.

- Ritsluiting dipilih dari mutu yang baik, agar awet di dalam pemakaiannya.

- Aksesoris tambahan dari bahan logam yang bermutu baik, tidak mudah luntur dan ukuran yang sesuai.

- Benang jahit jenis poliester, yang kuat tidak mudah putus, dan tidak luntur warnanya. juga jenis lem yang kuat diperlukan sebagai bahan pembantu untuk mempermudah penjahitan, lem harus berkwalitas baik, dengan daya rekatnya yang tinggi.

Pakaian kerja tersebut diatas dibuat dengan menggunakan bahan yang dipersyaratkan serta ditunjang oleh ketrampilan yang memadai, sehingga didapat jahitan yang rapi, tidak meloncat, kuat, tidak kendor, jarak jahitan teratur sehingga kesalahan yang terjadi hanya sedikit dan hanya terdapat pada bagian yang kurang penting misalnya sambungan pada bagian sisi lengan yang tidak tampak dari luar atau dapat juga terjadi, jarak jahitan dari tepi kulit kurang tepat, tetapi sambungan yang diletakkan pada bagian penting dibuat tepat. Dengan demikian didapat hasil jahitan yang rapi, oleh karena itu, pada bagian yang menumpuk harus dipukul lembut dengan menggunakan palu, agar didapat tebal tumpukan yang merata, yang perlu mendapatkan perlakuan ini adalah pada bagian saku atau pada bagian kerah, kadang perlu juga dilakukan penyesetan pada kulit untuk mengurangi ketebalan tersebut, setelah diseset kemudian dilem dengan rapi, agar proses penjahitan dapat berjalan dengan mudah dan lancar Mesin jahit yang sesuai perlu dipersiapkan, Karena penjahitan yang dilakukan dengan mesin yang tepat akan menghasilkan jahitan yang baik. Ketiga pakaian kerja kulit yang telah dibuat, untuk kerapian jahitan dinilai baik.

Sedangkan untuk kerapian pemasangan kain lapis, dapat tercapai dengan baik, kalau tidak bergelembung, jahitan rapi hal ini dapat dilaksanakan dengan bantuan jarum pentul yang berfungsi sebagai pegangan pada saat menjahit kain lapis dengan kulit. Kerapian pemasangan kain lapis model dua dan tiga dinilai baik, sedangkan model satu dinilai cukup baik, karena masih ditemui sebagian kain lapis yang tidak merata.

Pemasangan kancing dan ritsluiting, pada model dua dan tiga dinilai baik, karena kancing dan ritsluiting tepat pemasangannya, rapi jahitannya, kedua ujung pada bagian atas dan bawah dari ritsluiting terlihat rata, sehingga mudah untuk dibuka atau ditutup dan berfungsi dengan baik.

Sedangkan pada model satu, retsluiting sudah dipasang dengan baik, jahitan cukup rapi, akan tetapi sambungan pada bagian pinggang masih menggelembung yang diakibatkan adanya penumpukan yang agak berlebihan sehingga pemasangan ritsluiting terkesan kurang rata. Dengan demikian kerapihan pemasangan ritsluiting pada model satu dinilai cukup baik. Hasil Penilaian terhadap prototip pakaian kerja dapat dilihat pada tabel 1. 
Tabel 1. Hasil Penilaian

\begin{tabular}{|l|c|c|c|c|c|}
\hline $\begin{array}{l}\text { No } \\
\text { Urut }\end{array}$ & $\begin{array}{c}\text { Kerapihan } \\
\text { Penjahitan }\end{array}$ & $\begin{array}{c}\text { Pemasangan } \\
\text { Kain Lapis }\end{array}$ & $\begin{array}{c}\text { Pemasangan } \\
\text { Kancing/Katup Sleret }\end{array}$ & Model & $\begin{array}{c}\text { Penampilan } \\
\text { Umum }\end{array}$ \\
\hline 1 & Baik & Cukup & Cukup & Cukup & Cukup \\
2 & Baik & Baik & Baik & Baik & Baik \\
3 & Baik & Baik & Baik & Baik & Baik \\
\hline
\end{tabular}

\section{KESIMPULAN}

Berdasarkan Hasil Penelitian dapat disimpulkan bahwa dengan dipenuhinya persyaratan teknis akan dapat diwujudkan pakaian kerja kulit yang bermutu baik. Pakaian kerja model dua dan tiga dinilai baik, sedangkan model satu dinilai cukup.

Penelitian ini masih perlu dilanjutkan untuk mengetahui minat pasar terhadap pakaian kerja kulit ini, dengan menampilkan bahan dasar yang warnanya lebih menarik, seperti warna merah tua, dan dengan mencantumkan label perusahaan yang bersangkutan agar lebih spesifik.

\section{DAFTAR PUSTAKA}

SNI. 06-3538-1994 Mutu dan Cara Uji, Kulit Sarung Tangan Dan Jaket Domba Kambing. Dewan Standardisasi Nasional.

SNI. 06-0996-1989 Cara Uji Kekuatan Gosok Cat Tutup Kulit Jadi dengan Alat Crockmeter. Dewan Standardisasi Nasional.

Pallizzoto.C., 1989.Casual Wear Modelling. Project UNDP/UNIDO - INS/PS-016 for afficial course of IRDLAI, Yogyakarta.

Pallizzoto C., 1989. Tailoring Styles for Gents Leather Garment. Project UNDP/UNIDO - INS/PS - 016

Porrie Muliawan., 1982 Konstruksi Pakaian Busana Wanita. PT BPK Gunung Mulia. PP 57

Sotja Prajati, Simanungkalit R., Dian Dwiantari, 1991. Laporan Penelitian Pengembangan Desain Celana Panjang Pria dan Kulot dari Kulit, PPTIKKP. 


\section{Lampiran 1 HASIL PENILAIAN PANELIS}

\begin{tabular}{|c|c|c|c|c|}
\hline $\begin{array}{l}\text { No } \\
\text { Urut }\end{array}$ & $\begin{array}{l}\text { Kerapihan } \\
\text { Penjahitan }\end{array}$ & $\begin{array}{l}\text { Pemasangan } \\
\text { Kain Lapis }\end{array}$ & $\begin{array}{l}\text { Pemasangan } \\
\text { Kancing / Ritsluiting }\end{array}$ & Model \\
\hline 1. & $\begin{array}{l}A=0 \\
B=6 \\
C=4 \\
D=0 \\
E=0\end{array}$ & $\begin{array}{l}\mathrm{A}=0 \\
\mathrm{~B}=4 \\
\mathrm{C}=5 \\
\mathrm{D}=1 \\
\mathrm{E}=0\end{array}$ & $\begin{array}{l}A=0 \\
B=3 \\
C=6 \\
D=1 \\
E=0\end{array}$ & $\begin{array}{l}A=0 \\
B=2 \\
C=7 \\
D=1 \\
E=0\end{array}$ \\
\hline 2. & $\begin{array}{l}\mathrm{A}=1 \\
\mathrm{~B}=7 \\
\mathrm{C}=2 \\
\mathrm{D}=0 \\
\mathrm{E}=0\end{array}$ & $\begin{array}{l}A=0 \\
B=6 \\
C=3 \\
D=1 \\
E=0\end{array}$ & $\begin{array}{l}A=0 \\
B=0 \\
C=8 \\
D=2 \\
E=0\end{array}$ & $\begin{array}{l}A=0 \\
B=7 \\
C=2 \\
D=1 \\
E=0\end{array}$ \\
\hline 3. & $\begin{array}{l}\mathrm{A}=2 \\
\mathrm{~B}=6 \\
\mathrm{C}=2 \\
\mathrm{D}=0 \\
\mathrm{E}=0\end{array}$ & $\begin{array}{l}\mathrm{A}=0 \\
\mathrm{~B}=7 \\
\mathrm{C}=2 \\
\mathrm{D}=1 \\
\mathrm{E}=0\end{array}$ & $\begin{array}{l}A=0 \\
B=9 \\
C=1 \\
D=0 \\
E=0\end{array}$ & $\begin{array}{l}A=0 \\
B=8 \\
C=1 \\
D=1 \\
E=0\end{array}$ \\
\hline
\end{tabular}

\section{Catatan}

A nilai $5=($ Baik sekali $)$

B nilai $4=($ Baik $)$

C nilai $3=($ Cukup )

D nilai $2=($ Kurang $)$

E nilai $1=($ Kurang sekali $)$ 